\title{
Gestão de Pessoas em um Hospital Universitário após Adesão à EBSERH
}

\section{People Management in the University Hospital after Accession to EBSERH}

Renata Brocker de Paula ${ }^{1}$, Katia Denise Moreira², Irineu Manoel de Souza ${ }^{3}$ e Luci Mari Aparecida Rodrigues ${ }^{4}$ 1,2,3,4 Universidade Federal de Santa Catarina, UFSC 


\title{
Resumo
}

Considerada a implantação de um novo modelo de gestão hospitalar para os Hospitais Universitários (HUs) federais, a partir da chegada de uma empresa pública para administrá-los, inclusive naquilo que se refere à gestão de pessoas, este estudo objetiva conhecer a percepção dos gestores de uma dessas empresas, em termos de gestão de pessoas, após adesão à EBSERH. Metodologicamente, trata-se de um estudo de campo, de abordagem qualitativa, descritivo quanto aos objetivos, cujas técnicas de coleta de dados aplicadas foram a bibliográfica, documental e entrevista semiestruturada com os oito gestores principais da instituição. Os dados revelaram a complexidade em se gerir pessoas em um ambiente hospitalar, a falta de trabalhadores para atender a demanda de serviços e a tensão na transição da administração do hospital - de uma Instituição de Ensino Superior para a EBSERH. Os resultados mostraram que os gestores têm como principais preocupações: a administração das demissões dos profissionais fundacionais e a contratação de trabalhadores para suprir a lacuna deixada pelos primeiros, para fins de manutenção dos serviços oferecidos pela instituição, além da necessidade de desenvolvimento de uma política efetiva para gerir o pessoal.

Palavras-chave: hospitais públicos, administração de recursos humanos, hospital universitário

\begin{abstract}
Considering a new management model for Federal University Hospitals (HUs), which includes people management, this study aims to understand the manager's perception, about people management, after a University Hospital joined the EBSERH. Methodologically, this is a field study, associated to a qualitative and descriptive approach considering its objectives. For the data collection, the techniques applied were the bibliographical, documentary and semi-structured interviews applied to the eight main managers of the institution. The data revealed the people managing complexity within an environment that is already complex by nature and the lack of workers to meet the demand for services, and the strain of transition from HU / UFSC to EBSERH. Consequently, the results showed that when it comes to people management, the main issues considered by the managers are: the layoffs administration of the founding professionals and hiring workers to fill the gap left by the former ones, for maintaining the services offered by the institution, in addition to their need of developing an effective policy for managing the staff.
\end{abstract}

Keywords: public hospital, human resource management, university hospital 
A realidade atual naquilo que se refere ao número de pessoal contratado pelo Governo Federal para a prestação de serviços públicos, não difere daquilo que se tinha como cenário na década de 1980, ou seja, não há contratação de pessoas, por meio de concurso público, em número suficiente para execução dos trabalhos (Paula, 2016). Tal fato se estende para o contexto dos Hospitais Universitários (HUs) federais, local em que nos últimos anos houve inclusive a extinção de cargos, como forma de "enxugamento" da máquina administrativa pública (Universidade Federal de Santa Catarina [UFSC], 2013).

É importante lembrar que a saúde é o maior bem do indivíduo, definida como um estado pleno de bemestar físico, mental e social e não a simples ausência de doença (Organização Mundial da Saúde [OMS], 1946). Ao se considerar o contexto brasileiro, Cahali (2012) destaca que a má organização e funcionamento dos hospitais públicos atingem os cidadãos brasileiros que mais precisam desse serviço. $O$ autor acrescenta que as políticas públicas de saúde no Brasil são consideradas insatisfatórias pelos usuários da rede pública, uma consequência do investimento insuficiente por parte do Estado para suprir as necessidades da população.

Considerado o número crescente de pessoas que buscam os serviços de saúde por meio do Sistema Único de Saúde [SUS], os Hospitais Universitários expandiram a estrutura física, porém o Governo Federal, conforme já posto, não possibilitou a ampliação do quadro de pessoal, por meio de concurso público, fator essencial, para atender à demanda. Inclusive, nos últimos anos, cargos foram extintos e, por esta razão, vagas de pessoal antes repostas, foram "perdidas" (Paula, 2016).

A eminente necessidade de recuperação do cenário - demanda de atendimento versus pouco trabalhadores - exigiu dos gestores ações para suprir a necessidade de pessoal e, assim, as Universidades, com Hospitais Universitários vinculados a elas, passaram a contratar trabalhadores via fundações de apoio (UFSC, 2013), que de acordo com a Lei no 8.958/94, art. 1ㅇ, “[...] são instituídas com a finalidade de dar apoio a projetos de ensino, pesquisa e extensão e de desenvolvimento institucional, científico e tecnológico as Instituições Científicas e Tecnológicas (ICT)” (Lei n. 8.958, 1994). Todavia, os contratados por fundações de apoio caracterizam vínculo precário e, dessa forma, as Universidades deveriam repor o quadro de pessoal por meio de concurso público (Tribunal de Contas da União [TCU], 2011).

Vale destacar, que acerca dos HUs, o TCU emitiu parecer, cujo teor expressa que tais instituições vivenciavam uma crise gerencial e financeira (TCU, 2011). Ainda de acordo com o Órgão, tal situação dos hospitais se dá em função da insuficiência de recursos humanos; da precariedade no contrato de pessoal; da insuficiência orçamentária e da falta de autonomia, devido à dependência da estrutura da Universidade. Assim, com o propósito resolver, dentre outras questões, os problemas de pessoal no quadro de pessoal dos HUs, o Estado criou a Empresa Brasileira de Serviços Hospitalares [EBSERH], por meio da Lei n. 12.550/2011, de 15 de dezembro de 2011, uma empresa pública com o objetivo de administrar unidades hospitalares mediante contrato assinado com as Instituições Federais de Ensino (Lei n. 12.550, 2011).

Observa-se que o TCU expõe a exiguidade em termos de pessoas nos HUs, no entanto, é importante lembrar que a gestão de pessoas envolve muito mais do que a simples demanda de pessoal, trata-se de 
compreender a realidade organizacional, construir diretrizes e instrumentos para uma administração efetiva de pessoal (Dutra, 2002). Nesse sentido, o autor argumenta que as organizações devem priorizar [...] um modelo de gestão de pessoas que estimule e ofereça suporte ao desenvolvimento mútuo da empresa e das pessoas e que ofereça a ambas, orientação para esse desenvolvimento de forma clara, simples e flexível" (Dutra, 2002, p. 57).

A esse contexto insere-se o Hospital Universitário de uma Instituição de Ensino Superior do sul do país, que aderiu em 2016 a sua operacionalização pela EBSERH. Importante destacar que o processo foi longo e conflituoso, visto que parte da comunidade acadêmica considerava a adesão uma ação equivocada, que representava em termos gerais a privatização do serviço público (G1 Santa Catarina, 2016).

Assim, diante da problemática ora apresentada, ou seja, dos desafios enfrentados pela administração dos Hospitais Universitários em termos de gerir pessoas, incluindo não só demissões e contratações, mas também, o desenvolvimento do indivíduo no ambiente organizacional, associados a adesão de um novo modelo de gerenciamento para esse tipo de instituição (EBSERRH) emerge como questionamento deste estudo: qual a percepção dos gestores de um Hospital Universitário, em termos de gestão de pessoas, após adesão à EBSERH?

A fim de responder à questão de pesquisa, define-se como objetivo deste estudo conhecer a percepção dos gestores de um Hospital Universitário, em termos de gestão de pessoas, após adesão à EBSERH. Justifica-se o desenvolvimento desta pesquisa pela importância em se discutir a gestão de hospitais públicos, uma vez que, são referência na área da saúde, no contexto social em que se inserem. Considera-se também oportuno tratar, especificamente, da área que afeta a gestão de pessoas dos HUs, visto que a estrutura de pessoal é bastante heterogênea, pois é formada por profissionais de diversas áreas e especialidades, os quais são afetados diretamente pelas ações definidas pelo plano de gestão da EBSERH e, ainda, que os atos desses sujeitos têm consequências sobre toda a sociedade atendida pelos serviços prestados pelo hospital.

Em termos de estrutura, o estudo está dividido em cinco seções. Esta primeira introdutória, que contextualiza o tema, apresenta a problemática, os objetivos e a justificativa para o desenvolvimento da pesquisa. Na segunda seção, tem-se o arcabouço teórico que traz as unidades de gestão de pessoas e gestão de pessoas nos hospitais universitários. Na sequência são apresentados os procedimentos metodológicos utilizados para elaboração desta pesquisa. Na quarta seção está disposta à análise e discussão dos dados associadas aos resultados obtidos. As considerações finais, seguidas pelas referências utilizadas encerram o estudo.

\section{Gestão de Pessoas nas Organizações}

As organizações existem a partir da fusão entre o trabalho realizado pelas pessoas e os recursos financeiros, tecnológicos, de informação, estruturais e materiais - que elas utilizam para isso (Moraes, 2016). Nessa direção, é possível dizer que o indivíduo compõe a estrutura de uma organização e, sendo ele, parte fundamental, é necessária a reflexão, por parte dos gestores, sobre os princípios e práticas da gestão de pessoas.

Esse entendimento, segundo Dutra (2002) não é contemporâneo, já que a preocupação com as pessoas nas organizações acontece desde os tempos antigos, no entanto, é somente no final do século XVIII, que ganha significância e começa a ser explorado teoricamente. Em termos mundiais, países como a Inglaterra, a França e 
os Estados Unidos são os precursores em ações que envolvem a gestão de pessoas, todavia é no século XX, em território americano e, a partir da administração científica, que o fenômeno ganha solidez (Dutra, 2002).

Ao se analisar brevemente o processo evolutivo das ciências da administração é possível observar que as pessoas, apesar de sua essencialidade para o ambiente organizacional, nem sempre foram elevadas a níveis de importância, tanto que foram incluídas, primeiramente, em um departamento, conhecido como Recursos Humanos (RH), o qual tinha como função cumprir aquilo que os marcos legais exigiam, como por exemplo, contratação, avaliação e regularizações (Dutra, 2002). Assim, as pessoas, permaneceram por um longo período, marginalizadas, visto que o foco do gestor era o negócio propriamente dito, ou, em outras palavras, não havia o entendimento de que para o alcance do produto final era preciso do trabalho realizado pelas pessoas (Moreira, 2012). Na Figura 1, ilustra-se uma síntese de cada abordagem no campo das ciências da administração, associada às práticas para gestão de pessoas.

Figura 1

Características da prática de gestão de pessoas associada às abordagens da Administração

Abordagens

Abordagem Clássica

Administração Científica

Administração Geral

Abordagem Humanística

Abordagem Quantitativa

Abordagens Contemporânea

Sistêmica

Contingencial

Cultural
Definição da melhor maneira de cada trabalhador fazer melhor o seu trabalho.

Perspectiva da organização como um todo. Primeiras teorias gerais sobre o trabalho dos gerentes e sobre o que constituía a boa prática em administração.

Reconhecimento da importância do fator humano, para o sucesso no processo de produção e alcance de resultados.

Aplicações matemáticas e estatísticas na prática da administração.

Organização como um conjunto de partes (pessoas e recursos) inter-relacionadas e interdependentes dispostas de maneira a produzir uma totalidade unificada.

Reconhece que as práticas administrativas devem modificadas para dar conta dos fatores situacionais (gestão de pessoas).

Reconhecimento de que as organizações possuem culturas, além de crenças de que a compreensão da cultura de uma organização específica pode fornecer insights sobre o comportamento dos seus colaboradores.

Nota. Elaborado pelos autores a partir de Robbins (2001)

A partir do ilustrado na Figura 1 é possível concluir que as abordagens contemporâneas permitem ao indivíduo destacar-se, fazendo com que os gestores adotem novos posicionamentos em termos de administração de pessoal. Sobre esse movimento, Ferreira (2001, p. 18) explica que:

Do tradicional departamento de pessoal da década de 1950, passando pela divisão de relações industriais na década de 1960, à recente área de recursos humanos, assistimos atualmente a significativas mudanças de paradigma que apontam uma nova fase de gestão de pessoas. 
Ou seja, na abordagem sistêmica observa-se a tendência para as inter-relações (trabalho e trabalhador); na contingencial entende-se a necessidade de respeitar as contingências (características dos trabalhadores) e na cultural o comportamento cultural (também do trabalhador) é fato de apreciação. Nota-se, que o constructo teórico das ciências da administração direciona-se para reflexões sobre representatividade daqueles que alicerçam o processo de produção de uma organização e que, consequentemente, fazem com que os objetivos sejam alcançados - os indivíduos.

Entretanto, a gestão de pessoas é fenômeno complexo, visto que, a dificuldade está em superar a dominante visão tradicional da administração de recursos humanos que equipara as pessoas a recursos, tal qual, outros existentes em uma organização (Fleury \& Fischer, 1998). A complexidade está também, na necessidade em contemplar a gestão de pessoas, as diversas dimensões que abrangem os processos organizacionais, fato que demanda: gestão estratégica de pessoas; diagnóstico de padrões culturais; gestão de processos de captação, formação, movimentação e desenvolvimento de pessoas; gestão das relações de trabalho e da qualidade de vida no trabalho e gestão de competências (Fleury \& Fischer, 1998).

A gestão de pessoas é tema discutido no âmbito acadêmico, contudo é preciso garantir que a teoria alcance o campo empírico e reforce, cada vez mais, a essencialidade do indivíduo na composição organizacional. Vale destacar, que apesar da ainda dominação dos moldes mecanicistas (RH), há empresas contemporâneas que têm materializado a questão da importância das pessoas, inclusive, segundo Alles (2006), proporcionando a elas, a possibilidade de desenvolvimento de competências. No entanto, Leal e Dalmau (2014) alertam para a necessidade de mapeamento de competências tanto individuais, quanto organizacionais. Segundo os autores, trata-se de uma ferramenta que permite conhecer as competências que demandam desenvolvimento, no entanto, a internalização desse processo, depende da capacidade de absorção e da vontade humana.

\section{Gestão de Pessoas nos Hospitais Universitários Federais}

Antes de adentrar o campo dos HUs, é importante dizer que a tendência para o desenvolvimento das pessoas é considerada, também, pelas instituições públicas, uma vez que, atualmente, a administração pública brasileira está se adequando aos pressupostos do New Public Management, um movimento iniciado pela corrente teórica americana e inglesa, na década de 1980 (Hondeghem, Horton \& Scheepers, 2006). Afirmam as autoras, que essa nova tendência ganhou força no contexto brasileiro, a partir de 1989, em tempos de reforma administrativa do Estado.

Para Hondeghem, Horton e Scheepers (2006), o New Public Management é uma forma de gestão, que enfatiza a competência, como elemento-chave para a adequação do indivíduo as contínuas mudanças enfrentadas pelo setor público. De acordo com as autoras, a competência é a unidade transformadora da tradicional burocracia evidenciada no serviço público, visto que, a ela estão associadas à flexibilidade e a adaptabilidade.

Ao se tratar do quadro de pessoal de um Hospital Universitário, observa-se primeiramente, uma heterogenia acentuada, visto que a equipe abrange profissionais da área administrativa (formada por profissionais do campo de gestão); daquela de assistência (formada, por técnicos de enfermagem, enfermeiros e médicos); 
e de apoio assistencial (formada por nutricionistas, técnicos de laboratório, fisioterapeutas) (Empresa Brasileira de Serviços Hospitalares [EBSERH], 2016b). Além disso, existem regimes múltiplos de contratação: trabalhadores que são vinculados ao regime jurídico único, contratados via fundação de apoio e contratados por empresas terceirizadas (TCU, 2011).

Sobre a contratação via fundação de apoio ou por empresas terceirizadas, os HUs, não estão autorizados a prover, sob tal forma, a falta de profissionais em atividades assistenciais (Decreto n. 2.271, 1997). Nessa direção, a contratação de serviços pelas Autarquias é autorizada para: “[...] atividades de conservação, limpeza, segurança, vigilância, transportes, informática, copeiragem, recepção, reprografia, telecomunicações e manutenção de prédios, equipamentos e instalações serão, de preferência, objeto de execução indireta" (Decreto n. 2.271, 1997, s.p).

Em 2011, a força de trabalho dos Hospitais Universitários era composta por 70.373 profissionais, dos quais 26.556 eram fundacionais (TCU, 2011). Sobre este aspecto, Ribeiro, Bolzan, Littike e Sodré (2010) apontam algumas situações que desencadearam o problema de falta de pessoal nos HUs Federais, são elas: ausência de concursos públicos; falta de planejamento para reposição dos aposentados; alto nível de adoecimento e afastamento dos trabalhadores e salários incompatíveis com o mercado, fato que gerou a busca por novas oportunidades, sobretudo pelos contratados via fundação de apoio.

Vale destacar que Duarte e Botazzo (2009, p. 162) indicaram os principais problemas, que afetam a gestão de pessoas no Sistema Único de Saúde (sistema de saúde pública, ao qual os HUs estão associados), entre eles estão: regimes múltiplos de contratação, todavia sem distinção entre os trabalhadores, ou seja, todos trabalham sob as mesmas condições, mas em regimes de horários e salários diferenciados; inadequação quantitativa do quadro de pessoal, ou seja, insuficiência de funcionários; excesso de pessoal com baixa qualificação profissional e, consequentemente, falta de qualificação adequada; rotatividade de funcionários por transferências e afastamentos; absenteísmo e dupla militância; baixa motivação; ausência de sistemas de avaliação de desempenho, programas de incentivos e de ascensão profissional; treinamento e capacitação de pessoal sem foco definido e sem avaliação de impacto.

Interessante observar, que muitos dos problemas apontados vão ao encontro do posto por Bonacim e Araújo (2011), ou seja, que os profissionais que trabalham no ambiente hospitalar, principalmente, da área da assistência, geralmente não se consideram parte da equipe, por que o hospital é um lugar para exercer, simplesmente, suas habilidades, desta forma não criam uma identidade com o hospital. Ainda, de acordo com os autores, esta postura acaba criando conflitos entre os profissionais e o administrador, que tem o poder instituído.

Diante do exposto, foi possível observar que nos HUs, a gestão de pessoas vai em direção contrária àquilo que pretende o New Public Management. Assim, com a finalidade de reverter essa situação, o Governo Federal cria a Empresa Brasileira de Serviços Hospitalares (EBSERH), uma empresa pública, que de acordo com o Tribunal de Contas da União (2011), surge como solução na contratação e gestão de pessoal para os Hospitais Universitários Federais. 


\section{Metodologia}

Em termos metodológicos esta pesquisa se caracteriza como de abordagem qualitativa, visto que tem o intuito de conhecer um fenômeno específico, o da gestão de pessoas, em um ambiente determinado, a partir do significado que os atores sociais pertencentes ao espaço dão ao processo. Esse tipo de abordagem, segundo Creswell (2009), tem o objetivo de compreender os significados que indivíduos ou grupos conferem a situações em que se inserem.

Diante de tal escolha, o estudo é descritivo, visto que se expõem características inerentes de um determinado fenômeno ou população (Vergara, 2007), neste caso, a gestão de pessoas e os trabalhadores de um HU Federal administrado pela EBSERH. Como estratégia de estudo fez-se uso do estudo de campo, o qual, segundo Gil (2010), busca o aprofundamento de uma realidade específica. Assim, desenvolveu-se o estudo no Hospital Universitário Prof. Polydoro Ernani de São Thiago, da Universidade Federal de Santa Catarina (HU/UFSC), no período de dezembro de 2015 a fevereiro de 2016.

Em termos de coleta de dados, utilizou-se a bibliográfica, a documental e a pesquisa de campo, por meio de aplicação de entrevistas semiestruturadas. Na primeira buscaram-se em materiais sistematizados, provenientes de bases compostas por materiais publicados, tais como livros, artigos de revistas e de periódicos científicos (Vergara, 2007), teoria sobre gestão de pessoas. Na segunda, caracterizada pela busca de dados em registros e documentos (Vergara, 2007) explorou-se material sobre os HUs e a EBSERH.

No que se refere às entrevistas, o intuito foi o de averiguar, a partir da percepção dos sujeitos, os desafios relacionados ao quadro de pessoal, funcionários contratados via fundação de apoio, cedência dos servidores à EBSERH, contratações via EBSERH e absenteísmo. Acerca dos sujeitos da pesquisa, foram escolhidos os oito gestores vinculados a Direção Geral do HU/UFSC. A justificativa para escolha dos sujeitos foi a de que esse grupo é o responsável pela gestão principal do HU/UFSC. Foi garantido aos entrevistados o anonimato e, sendo assim, os sujeitos foram identificados como Entrevistado, seguido de um número cardinal (Entrevistado 1, Entrevistado 2... Entrevistado 8).

A análise de conteúdo foi a escolha para tratamento dos dados. De acordo com Bardin (2011), tal método viabiliza a sistematização do conteúdo das mensagens ou expressões, alicerçados em índices passíveis ou não de quantificação, a partir de técnicas, que permitem ao analista ter a sua disposição ou criar, operações analíticas, adaptáveis a aquilo que se procura resolver. Assim, buscou-se a partir da mensagem dos sujeitos, compreender suas próprias percepções sobre a gestão de pessoas no Hospital Universitário da UFSC, após a adesão à EBSERH. Na sequência, são apresentados e analisados os dados, bem como apresentados os resultados deste estudo.

\section{Análise dos Dados e Resultados}

Anterior à análise dos dados e resultados propriamente dita faz-se uma breve contextualização sobre a gestão de pessoas em termos de EBSERH e na sequência sobre a situação do quadro de pessoal do HU/UFSC. Assim, a EBSERH é uma empresa pública de direito privado, criada pelo Governo Federal por meio da Lei n. 12.550, de 15 de dezembro de 2011 (EBSERH, 2014). O dispositivo legal tem por finalidade prestar gratuitamente os serviços 
de assistência médico-hospitalar, ambulatorial e de apoio diagnóstico e terapêutico à comunidade (Lei n. 12.550, 2011). É também, um propósito da Empresa:

[...] a prestação às instituições públicas federais de ensino ou instituições congêneres de serviços de apoio ao ensino, à pesquisa e à extensão, ao ensino-aprendizagem e à formação de pessoas no campo da saúde pública, observada, nos termos do art. 207 da Constituição Federal, a autonomia universitária (Lei n. $12.550,2011$, s.p.).

Em síntese, trata-se de apresentar um novo modelo de gestão hospitalar para os Hospitais Universitários, incluindo-se ao processo, a solução para a reposição de trabalhadores, os quais se enquadram no vínculo celetista (Lei n. 12.550, 2011). Vale lembrar, que o regime de trabalho celetista é regido pela Consolidação das Leis Trabalhistas (CLT) e o vínculo empregatício é contratual entre empregado e administração, e neste caso, é equiparada ao empregador particular. O empregado público, então, tem todos os direitos garantidos, tal qual um empregado celetista (Meirelles, 1997; Martins, 2007). No entanto, destaca-se sobre a forma de contratação que:

Art. 10. O regime de pessoal permanente da EBSERH será o da Consolidação das Leis do Trabalho - CLT, aprovada pelo Decreto-Lei $n^{\circ} 5.452$, de $1^{\circ}$ de maio de 1943 , e legislação complementar, condicionada a contratação à prévia aprovação em concurso público de provas ou de provas e títulos, observadas as normas específicas editadas pelo Conselho de Administração (Lei n. 12.550, 2011, s.p).

De acordo com o TCU (2011), a EBSERH não finalizou o processo de contratação de pessoal, por fundações de apoio ou empresas terceirizadas, nos HUs Federais com contratos firmados com menos de um ano. Nesse sentido, admitiram-se 11.809 profissionais concursados e, em contrapartida, foram demitidos 3.680 fundacionais (TCU, 2011). Ainda, de acordo com o Tribunal, alguns dos motivos que impedem ou dificultam a demissão imediata dos trabalhadores fundacionais é o impacto financeiro para efetuar o desligamento e a necessidade de transferência de conhecimento aos novos trabalhadores, concursados via EBSERH. Sobre os servidores que trabalham nos HUs Federais regidos pelo regime jurídico único, poderem ser cedidos à EBSERH, sem alteração do regime de trabalho original (EBSERH, 2014) há o entendimento de que:

[...] os servidores públicos em exercício no Hospital na data da assinatura do contrato permanecerão em seus postos, exercendo as mesmas atividades, e continuarão sujeitos ao regime previsto na Lei $\mathrm{n}^{\circ}$ 8.112/1990, inclusive quanto aos deveres, proibições e regime disciplinar, descritos na mesma Lei, vedado qualquer hipótese de desvio de função (EBSERH, 2014, s.p.).

É importante dizer que, a partir da assinatura do contrato, a EBSERH tem o prazo de doze meses para elaborar um plano de reestruturação para o hospital, no entanto, a instalação da empresa é imediata e, para fins de não prejudicar os trabalhos, podem ocorrer processos seletivos simplificados, por meio de análise curricular (EBSERH, 2014). As Universidades, por sua vez, que possuem contrato com a EBSERH têm o prazo de noventa dias para formalizarem a cessão de todos os servidores que atuam no âmbito dos Hospitais Universitários filiados à empresa pública (TCU, 2015). 
Lembra-se ainda, que nos HUs Federais, o corpo docente não está vinculado ao quadro de pessoal, pois este cargo pertence às Universidades Públicas Federais (EBSERH, 2014). Todavia, os docentes continuam tendo acesso ao ambiente, para desenvolver as atividades de ensino, pesquisa e extensão (EBSERH, 2014). Observa-se que não há uma definição para a gestão de pessoas naquilo que normatiza a EBSERH, há apenas definição sobre o recrutamento e seleção dos trabalhadores.

Em relação ao Hospital em estudo, a instituição contava no mês de julho de 2016, com: a) 1.318 servidores permanentes regidos pelo regime jurídico único; b) 109 trabalhadores contratados pela Fundação de Amparo à Pesquisa e Extensão Universitária (FAPEU); e c) 340 trabalhadores terceirizados das áreas de limpeza, segurança e recepção (UFSC, 2016). Ou seja, para suprir a falta de servidores e viabilizar as atividades assistenciais, o HU/ UFSC contratava pessoal por meio da Fundação de Apoio. Entretanto, no ano de 2015, o Tribunal de Contas da União, por meio do Acórdão 2983-46/2015, orientou que os fundacionais deveriam ser substituídos por servidores permanentes, contratados por concurso público (TCU/2015).

Entretanto, conforme já exposto, nos últimos anos, há uma restrição do Estado, para abertura de concursos públicos e, sendo assim, não houve o reposicionamento de vagas, para os casos de cargos extintos. Tal fato associado à demissão de cinquenta e cinco trabalhadores de fundação de apoio, ocorridas em dezembro de 2016, ao afastado de trabalhadores para tratamento de saúde e a não possibilidade de pagamento de hora extra, o HU/ UFSC tem utilizado o Adicional por Plantão Hospitalar (APH) para cobrir as escalas na assistência.

A APH é regulamentada por meio da Lei n. 11.907/2009 e com nova redação pela Lei n. 12.155/2009, que concede pagamento adicional aos servidores de Hospitais Universitários que estão no exercício das atividades hospitalares, "desempenhadas em regime de plantão nas áreas indispensáveis ao funcionamento ininterrupto [...]" (Lei n. 11.907, 2009). Nessa situação, estão 282 trabalhadores das áreas de enfermagem, de apoio assistencial e diagnóstico complementar (UFSC, 2014).

Diante de tal situação, a UFSC, após um processo longo e conflituoso, conforme mencionado introdutoriamente, confirma sua adesão à EBSERH. Desse modo, no dia 16 de março de 2016 é assinado o contrato entre a Universidade Federal de Santa Catarina (UFSC) e a Empresa Brasileira de Serviços Hospitalares (EBSERH), que tem por objetivo a gestão especial gratuita do Hospital Universitário Professor Polydoro Ernani de São Thiago, compreendendo: a atuação como campo de ensino, pesquisa e extensão nas áreas da saúde e afins da UFSC; garantia da oferta, à população, de assistência médico-hospitalar, ambulatorial e de apoio diagnóstico e terapêutico, integral e exclusivamente no âmbito do SUS; e implementação de sistema de gestão único, com geração de indicadores quantitativos e qualitativos para o estabelecimento de metas (EBSERH, 2016a). Quanto ao quantitativo de pessoal, a proposta da EBSERH para o HU/UFSC é a contratação de 489 trabalhadores, no regime celetista (Dimensionamento, 2016).

Perante o verificado no ambiente de estudo foram realizadas entrevistas a fim de conhecer, a percepção dos gestores principais e, daqueles responsáveis pelas diretorias vinculadas, sobre os desafios de gerir o HU/UFSC, nessas condições. As respostas foram sintetizadas na Figura 2: 
Figura 2

Síntese das entrevistas dos atores sociais sobre o questionamento dos desafios na gestão do HU/UFSC.

Entrevistado

Entrevistado 1 (E1)

Entrevistado 2 (E2)

Entrevistado 3 (E3)

Entrevistado 4 (E4)

Entrevistado 5 (E5)

Entrevistado 6 (E6)

Entrevistado 7 (E7)
Resposta

Os desafios são inúmeros. Os hospitais são situados na chamada área de serviços. Nas áreas de serviço $70 \%$ dos problemas e das soluções, dos custos estão ligados a pessoas. Embora cada vez mais você esteja tendo, nos últimos anos um forte aumento dos custos em virtude da incorporação tecnológica.

Vários desafios e vários problemas que enfrentamos. O regime jurídico único, ao logo do tempo, dá ênfase aos direitos das pessoas do que aos deveres.

[...] com relação também a gestão de pessoas, eu acho que aqui dentro do HU, os serviços são muito fragmentados, cada um trabalha no seu espaço, no seu nicho, não existe uma visão única de instituição, de política da instituição, da visão e da missão da instituição. [...]. Os servidores da diretoria de administração e da enfermagem são mais vinculados a vida da instituição. Os médicos são mais desvinculados.

O fato é que tem uma demora muito grande entre o concurso e as aposentadorias. Então, de certa forma temos uma dificuldade por que só depois da aposentadoria do servidor é que começamos com tratativas para reposição. Sem considerar a questão dos auxiliares de enfermagem, de saúde, de laboratório e de farmácia, que pela complexidade do hospital, não temos realizado mais concurso. Então, de fato isso fez com que o HU perdesse a sua capacidade de crescimento, por que tudo que a gente precisa implantar o que nós definimos como visão, é ser um centro de referência de alta complexidade. E tudo que pretendemos expandir é exigido uma equipe multiprofissional e para conseguir habilitação do serviço especializado, nós precisamos de pessoal.

O HU/UFSC tem um grande déficit de pessoal. Os concursos públicos dependem de autorização do Governo Federal, que, a partir de 2010, autorizou concurso para repor aposentadorias, óbitos e exonerações. [...] se considerarmos o que tínhamos em 2008 e 2010, houve um aumento não significativo de servidores para o crescimento que o HU, e precisava ter para implantação das habilitações de alta complexidade. Então, as dificuldades são muitas. Nós não temos uma capacidade de reabrir leitos sem um aumento significativo de pessoal.

[...] hoje nós temos um estatutário que pode chegar amanhã e dizer que está indo embora e pode sair, só que eu não tenho na retaguarda possibilidade de contratar outro. Essa possibilidade não existe, mas a possibilidade da demissão é a qualquer hora e sem aviso prévio, em relação ao estatutário. Em relação ao celetista, ele dá aviso prévio e eu tenho pelo menos a possibilidade, e eu imagino que nós teremos, uma possibilidade de viabilidade de substituição dessa força de trabalho.

déficit de pessoal do HU/UFSC é grande. A contratação de servidores é demorada por que não se consegue realizar a reposição automática; a reabertura de leitos, expansão de serviços e habilitação de serviços especializados depende da contratação de equipe multiprofissional. 
Entrevistado

Resposta

Entrevistado 8 (E8) O governo federal deixou de mandar recursos e também não abriu concursos, consequentemente o número de pessoas que o HU precisa não foi contratado e impacta nas áreas fechadas [...]

Nota. Pesquisa dos autores (2016)

Sobre a percepção dos gestores em termos de desafios, subtrai-se do discurso de E4, E5, E6 e E7 a questão do déficit de pessoal, inclusive relatam as situações que desencadearam tal problema. Constata-se que elas estão de acordo com o posto por Ribeiro at al. (2010), como, por exemplo, a ausência de concursos públicos; falta de planejamento para reposição dos aposentados; alto nível de adoecimento e afastamento dos trabalhadores e salários incompatíveis com o mercado, fato que gera a busca de outras oportunidades, sobretudo, pelos contratados via fundação de apoio.

Entretanto, a maioria dos gestores destaca a falta de concurso para preenchimento do quadro de pessoal como maior desafio enfrentado, todavia, cabe refletir também, sobre os fatores subjetivos que envolvem essa questão, quais sejam, por que concursos públicos não são realizados pelo Governo Federal? Há falta de planejamento por parte dos órgãos superiores ou há falta de interesse? Outra questão que envolve diretamente a gestão de pessoas o absenteísmo e o adoecimento dos servidores citado pelos gestores é consequência única da estafa por excesso de trabalho, devido à falta de pessoal ou existem outros elementos ocultos que ancoram essa situação? Ou seja, a gestão de pessoas, neste caso, está apenas voltada a questão de suprir a falta de pessoal e não em conhecer as inter-relações que afetam a conjuntura. Também, a não aproximação com as abordagens mais contemporâneas (que pregam uma visão sistema da organização) está expressa na fala de E3 (2016), quando trata da "fragmentação" entre os setores "[...] Com relação também a gestão de pessoas, eu acho que aqui dentro do HU, os serviços são muito fragmentados, cada um trabalha no seu espaço, no seu nicho, não existe uma visão única de instituição, de política da instituição, da visão e da missão da instituição".

Ressalta-se ainda, do expresso por E1 a identificação de que 70\% dos problemas e das soluções estão associados às pessoas, naquilo que se refere as áreas de serviço. Um exemplo disso é a consulta médica, pois mesmo que a tecnologia permita o agendamento eletrônico e exames detalhados, a ação fim é a resolução da falta de saúde do cidadão, que vai ser diagnosticado e tratado pelo profissional de saúde, que é uma pessoa, que pode ter faltado ao trabalho ou não existir. Ou seja, é um problema o médico não atuar, naquilo que ele é referência para soluções.

Observa-se que tal qual outras organizações, as pessoas têm papel fundamental na composição e funcionamento dos HUs e, sendo assim, o modo de geri-las deveria ser uma prioridade para a instituição. Assim como ressaltam Fleury e Fischer (1998), a complexidade em gerir pessoas está na necessidade em inserir o indivíduo as diversas dimensões que abrangem os processos organizacionais, uma vez que, sem eles o sistema não funciona. Outra pergunta feita aos sujeitos da pesquisa foi sobre a manutenção dos servidores no HU/UFSC, sob gestão EBSERH. A Figura 3 apresenta as respostas, sintetizadas. 
Figura 3

Síntese das entrevistas dos atores sociais sobre a manutenção dos servidores no HU/UFSC, sob a gestão EBSERH.

\begin{tabular}{cc}
\hline Entrevistado & Resposta \\
\hline Entrevistado 1 (E1) $\quad$ Como é uma questão de interpretação jurídica, fica muito difícil emitir qualquer juízo de valor. Do \\
ponto de vista teórico, isso pode ocorrer, por que o servidor público federal, não precisa nem \\
voltar para a UFSC, ele pode pedir para ir para outra cidade, outro estado, outro lugar, onde \\
tenha cônjuge, isso é Lei e a Lei faculta isso.
\end{tabular}

Entrevistado 2 (E2) Os servidores serão cedidos para a EBSERH, mas nada impede que a UFSC possa solicitar a remoção interna de servidores, apesar dos servidores que estão no HU, terem mais conhecimentos e habilidades nos trabalhos realizados aqui, preferencialmente, eles deveriam aplicar esses conhecimentos no hospital, mas para a área meio, nada impede que a UFSC possa requerer servidores para atender as demandas da própria UFSC.

Entrevistado 3 (E3) A princípio sim, eles serão cedidos à EBSERH. Eu acho que a possibilidade de remoção para a UFSC deve acontecer agora, antes da adesão. Pelo o que eu entendo do processo de adesão, os servidores do HU têm essa opção de serem transferidos para a UFSC ou serem cedidos à EBSERH.

Entrevistado 4 (E4) Eu não sei te responder com toda segurança sobre isso. Em princípio, a ideia é que não exista mais essa possibilidade. Isso existiu lá no começo quando iniciou o processo de adesão, mas hoje isso já foi revogado, não tem mais como ceder.

Entrevistado 5 (E5) Eu fiz uma consulta à EBSERH, se a universidade quisesse ficar com algum quantitativo de servidores, eles responderam que estava sendo tratado por meio da ANDIFES (Associação Nacional de Dirigentes de Instituições de Ensino Superior). A princípio, com o relatório e recomendação do acórdão do TCU, referente aos novos contratos da EBSERH, a contratante tem que entregar a relação nominal dos servidores que serão cedidos. É claro que os profissionais da área médica e da enfermagem, a universidade não tem como absorver.

Entrevistado 6 (E6) A opção de cedência está prevista no modelo de contrato da EBSERH

Entrevistado 7 (E7) [...] quem quisesse retornar para a UFSC, poderia ir, principalmente aqueles que o seu cargo permite a equivalência na UFSC.

Entrevistado 8 (E8) Eu não saberia dizer. Eu não conheço tão bem o regulamento da EBSERH.

Nota. Pesquisa dos autores (2016)

Observa-se que há varias percepções dos gestores sobre essa temática. Alguns acreditam que a permanência ou não dos servidores do HU/UFSC após a implantação da gestão sob os moldes da EBSERH dependerá da opção que eles próprios fizerem. Já outros dizem que haverá cessões, enquanto um acredita que esse processo não acontecerá. Ressalta-se que está se tratando, neste caso, dos trabalhadores em regime jurídico único, enquanto a contratação via EBSERH é celetista (Lei n. 12.550, 2011). Nesse sentido, cabe a precaução de E1 (2016) quando diz que se trata de uma “[...] questão de interpretação jurídica, fica muito difícil emitir qualquer juízo de valor. Do ponto de vista teórico, isso pode ocorrer, por que o servidor público federal, não precisa nem voltar para 
a UFSC, ele pode pedir para ir para outra cidade, outro estado, outro lugar, onde tenha cônjuge, isso é Lei e a Lei faculta isso".

Todavia, a própria EBSERH ameniza a dúvida quando dispõe que os servidores que trabalham nos HUs Federais regidos pelo regime jurídico único, podem ser cedidos à EBSERH, sem alteração do regime de trabalho original (EBSERH, 2014). Tal entendimento está disposto no contrato firmado entre a empresa e a instituição. Ou seja, mesmo havendo discordância entre os gestores sobre a manutenção dos servidores no HU/UFSC, sob gestão EBSERH, acredita-se que caberá a eles a escolha, salvo casos em que a "[...] universidade não tem como absorver" (E5, 2016).

Na sequência, os sujeitos foram indagados, sobre os impactos nos serviços a partir da obrigatoriedade em demitir pessoas com contrato fundacional e admitir por meio de concurso público, uma vez que esse processo não acontece de forma totalmente simultânea. Na Figura 4, estão dispostas as respostas dos sujeitos de maneira condensada.

\section{Figura 4}

Síntese das entrevistas dos atores sociais sobre os impactos nos serviços com a demissão de pessoal com contrato fundacional.

\begin{tabular}{cc}
\hline Entrevistado & Resposta \\
\hline Entrevistado 1 (E1) $\quad$ Quando você tem um corpo funcional com pessoas da FAPEU com 10, 15 anos de casa, o impacto \\
é parecido quando perdemos um trabalhador de alto valor agregado, com muita experiência \\
dentro da instituição. Talvez uma das áreas do serviço público com maior demissão é nos \\
hospitais, sempre que você perde bons profissionais, você sofre com isso.
\end{tabular}

Entrevistado 2 (E2) Pela experiência que esses profissionais acabaram adquirindo ao longo dos anos, obviamente isso vai prejudicar bastante a instituição. Por outro lado, espero que a substituição deles seja feita gradualmente, para que a instituição possa assimilar isso com menos prejuízo.

Entrevistado 3 (E3) Há 40 médicos fundacionais no HU, a demissão dos fundacionais impacta significativamente nas Emergências, inviabilizando a continuidade dos atendimentos.

Entrevistado 4 (E4) Sem reposição o impacto é o fechamento de Unidades, não existe outra saída. A manutenção dos trabalhadores FAPEUS é essencial, para que não ocorra o fechamento de novos serviços.

Entrevistado 5 (E5) O impacto já foi sentido em 2015. Nós tínhamos 155 FAPEUS e baixamos para 100, por questões financeiras. O que nós temos aumentado é o quantitativo de APH, com isso estamos sobrecarregando os servidores para não fechar mais nada. [...]. Mas o impacto já aconteceu, eram 14 leitos abertos de UTI, passamos para 12. A gente só não fechou por que estamos gastando bastante APH. Mas quem está trabalhando já está sobrecarregado, está adoecendo.

Entrevistado 6 (E6) Eu acredito que tenha um impacto enorme, porque temos ótimos trabalhadores, extremamente envolvidos e que vão ter uma dificuldade muito grande de inserção no mercado de trabalho, uma vez que trabalharam muitos anos conosco e estão com idade muito difícil de ser reintegrado no mercado de trabalho. 
Entrevistado

Entrevistado 7 (E7)

Entrevistado 8 (E8)
Resposta

[...] se a gente não renovasse esse contrato (trabalhadores fundacionais), provavelmente, seria o fechamento da emergência. Qualquer época do ano o fechamento da emergência seria impactante, imagina fechar a emergência com a cidade cheia de turistas, então, seria catastrófico.

Eu acho que as contratações via FAPEU tem um impacto grande no HU por que nós contamos com a força de trabalho desses profissionais e desde o momento da sua contratação, eles sofrem com a situação de ser ou não demitidos, eles sempre tiveram uma agonia com relação a isso.

Nota. Pesquisa dos autores (2016)

Com base na resposta dos Entrevistados, dispostas na Figura 4, é possível aferir, que a manutenção dos serviços praticados pelo HU/UFSC implica na manutenção dos trabalhadores fundacionais até a realização de concurso público pela EBSERH, caso contrário, pode ocorrer fechamento de leitos ou Unidades. Nesse sentido, faz-se importante lembrar que, a partir da assinatura do contrato do HU/UFSC com a EBSERH, o prazo para a elaboração de um plano de reestruturação para o hospital é de doze meses, todavia, a instalação da empresa é imediata e, para evitar prejuízos nos trabalhos, preveem-se processos seletivos simplificados, por meio de análise curricular (EBSERH, 2014).

Suportado por tal possibilidade, definiu-se que o hospital vai manter contrato parcial com a fundação de apoio e manter em torno de 100 profissionais (E1, 2015). Ainda, segundo E1, a previsão é que as contratações via EBSERH ocorram no decorrer do primeiro semestre de 2016. Entretanto, algumas perdas, infelizmente, irão ocorrer, provavelmente, acentuadas por algumas aposentadorias que ocorrerão nesse período e isso vai nos gerar transtornos em alguns setores do hospital $(E 1,2015)$. Principalmente "Pela experiência que esses profissionais acabaram adquirindo ao longo dos anos [...]" (E2, 2016) e porque são “[...] ótimos trabalhadores, extremamente envolvidos [...]" (E6, 2016).

Cabe, ainda, reflexão sobre a fala de E6, quando aponta que os servidores fundacionais demitidos "[...] vão ter uma dificuldade muito grande de inserção no mercado de trabalho, uma vez que trabalharam muitos anos conosco e estão com idade muito difícil de ser reintegrado no mercado de trabalho" (E6, 2016). Percebe-se em E6 a preocupação com o ser humano e, em E1, E2 e E6 a questão das competências desses profissionais, todavia, para fins de atendimento a regulamentação legal, não há como a EBSERH absorver esses profissionais sem a realização de concurso específico.

Nos discursos observa-se tendências contemporâneas para a gestão de pessoas, que contemplam o indivíduo e sua experiência como fator importante para o ambiente organizacional. Desse modo, surge o questionamento: a não adoção de uma política para gerir pessoas é uma ação dos gestores ou as regulamentações e falta de recursos impedem que sejam pensadas, visto a prioridade de suprir a demanda de pessoal? Na fala de E5 (2016), sobre a sobrecarga de trabalho dos “[...] servidores para não fechar mais nada”, devido a diminuição dos profissionais fundacionais [...] mas o impacto já aconteceu, eram 14 leitos abertos de UTI, passamos 
para 12. A gente só não fechou por que estamos gastando bastante APH. Mas quem está trabalhando já está sobrecarregado, está adoecendo" (E5, 2016), observa-se que uma situação é consequência da outra. Em outras palavras, os servidores adoecem por excesso de trabalho, os gestores precisam agir para suprir essa lacuna e, não há uma prática de gestão que compreenda que a cultura de uma organização específica pode fornecer insights sobre o comportamento dos seus colaboradores (Robbins, 2001). É importante lembrar que o adoecimento dos trabalhadores envolve tanto a saúde física, como mental.

A última indagação aos sujeitos teve o intuito de averiguar, quais eram os desafios, em termos de gestão de pessoas, a partir da circunstância em que se encontrava o HU/UFSC, comparada ao pós-adesão à EBSERH. A Figura 5, expõe, de forma compilada as respostas dos entrevistados.

\section{Figura 5}

Síntese das entrevistas dos atores sociais, sobre o desafio da gestão de pessoas no HU/UFSC, após adesão a EBSERH.

\begin{tabular}{ll}
\hline Entrevistado & \multicolumn{1}{c}{ Resposta } \\
\hline Entrevistado 1 (E1) $\quad[. .$.$] um dos problemas de gestão de pessoas nos Hospitais Universitários é a existência conflituosa$ \\
entre o poder técnico e o poder administrativo. A gestão hospitalar é complexa, os hospitais \\
são considerados como instituições mais complexas da Administração. [...] as pessoas \\
trabalham aqui e trabalham em outras unidades e com isso elas têm identidade de exercício \\
profissional e não trabalham exatamente como equipe, trabalham com individualidade. \\
Quando você pede para alguém fazer Procedimentos Operacionais (POp), eles não querem \\
fazer. Por que cada um tem um Pop de maneira diferente. E quando você diz que tem que \\
fazer um, entre eles, não há um consenso, porque entre eles, eles fazem diferente.
\end{tabular}

Entrevistado 2 (E2) Espera-se que as substituições de pessoal sejam feitas gradativamente para que não haja maior impacto, para que a Instituição possa assimilar isso com menos prejuízo.

Entrevistado 3 (E3) Gestão de pessoas é muito complexo. Nós temos um hospital com uma herança cultural antiga, da forma de trabalho antiga. As pessoas vêm com uma mentalidade ainda voltada para uma assistência ainda que não está vinculada a rede, que não respeita fluxos, que não respeita regulação. E nós estamos nesse processo de mudar o modo de assistência. Nós temos que profissionalizar o hospital, tem que fazer ele funcionar dentro dos moldes da regulação, ser inserido na rede, fazer referência e contra referência. [...] com relação também a gestão de pessoas, eu acho que aqui dentro do HU, os serviços são muito fragmentados, cada um trabalha no seu espaço, no seu nicho, não existe uma visão única de instituição, de política da instituição, da visão e da missão da instituição. [...]. Os servidores da diretoria de administração e da enfermagem são mais vinculados à vida da instituição. Os médicos são mais desvinculados. 

na estrutura hospitalar que chega hoje a níveis absurdos de $20 \%$, quando o aceitável é em torno de 3\%. Então, esse é um desafio muito grande. Conseguir trabalhar com essa perspectiva de absenteísmo que tem sido uma constante no gerenciamento. Também tivemos, no decorrer dos últimos anos, alguns ganhos trabalhistas, como por exemplo, a licença gestação de 6 meses, mas não houve um acompanhamento de previsão de dimensionamento para cobrir isso, bem como do acompanhamento familiar do doente e da gestante ter que se afastar da assistência. Então tudo isso veio em benefício do trabalhador, mas não houve uma revisão dos cálculos de pessoal necessário para essas situações.

Entrevistado 5 (E5) [...] não é só recontratar, a gente tem que capacitar.

Entrevistado 6 (E6) As substituições poderiam ser gradativas, para que os trabalhadores contratados via Fapeu pudessem repassar o conhecimento aos novos contratados.

Entrevistado 7 (E7)

O HU tem um grande déficit de servidores, tanto que estamos com leitos fechados por causa disso. Nos últimos 3 anos, o hospital envelheceu, por que o hospital completou 35 anos e a população que trabalha nele chegou no momento crítico de aposentadoria e nós não tivemos as reposições no mesmo nível que precisávamos para manter o hospital.

Entrevistado 8 (E8) [...] porque a história de cada servidor ser autônomo e decidir fazer o seu horário, o seu jeito de trabalhar ou não ter regras, isso precisa ser olhado, por que o gestor é cobrado de acordo com a lei.

Nota. Pesquisa dos autores (2016)

A complexidade na gestão de pessoas é evidenciada pelos entrevistados. No caso do HU/UFSC é explícita a dificuldade que os gestores têm, em termos de superação da visão tradicional da administração de recursos humanos (Fleury \& Fischer, 1998). Observa-se inclusive que é preciso gerenciar conflitos interpessoais neste caso, afetando, inclusive a implantação de POps, já que cada indivíduo acredita que a sua maneira de realizar um procedimento é a melhor (E1, 2016).

Ainda, de acordo com E1, há conflitos entre o poder técnico e o administrativo, nesse sentido, quanto mais especialista for o profissional, mais ele tem poder perante a equipe e os gestores da Direção Geral são vistos, por eles, como controladores, que só fazem normas, uma confirmação da visão tradicionalista de administração. Vale lembrar que a gestão de divergências não é uma ação contemplada pelo setor de Recursos Humanos, visto que sua função é cumprir aquilo que os marcos legais exigiam, como por exemplo, contratação, avaliação e regularizações (Dutra, 2002). Em outras palavras, para a solução de conflitos é preciso desenvolver forma adequadas de geri-los, por meio de uma política de gestão de pessoas.

A proposta do parágrafo anterior tem ainda a finalidade de tratar o absenteísmo, apontado por E4, como um desafio para a gestão de pessoas, que no HU/UFSC chega a $20 \%$ a.a, quando a média de outras instituições é de $3 \%$ a.a, além de outros tipos de afastamentos (que alcançam índices elevados): licença para tratamento de saúde, doença pessoa na família e atestado médico; licença para adoção e licença maternidade; faltas injustificadas; 
licença casamento, licença paternidade e licença nojo (UFSC, 2014). Acredita-se que as situações de conflito e absenteísmo podem ser associadas ao exposto por Bonacim e Araújo (2011), sobre os profissionais vinculados a um ambiente hospitalar, principalmente da área da assistência, não se sentirem pertencentes ou identificados com o hospital, visto que se trata de um lugar em que simplesmente põem em prática suas habilidades. Nesse sentido, E5 (2016) menciona que em termos de gestão de pessoas, não basta apenas contratar, é preciso também capacitar. Considera-se que a ação de promover o desenvolvimento do indivíduo se ajusta ao preconizado pelo New Public Management, que traz a concepção do desenvolvimento da competência do indivíduo como unidade transformadora, fato que possibilita a flexibilidade e a adaptabilidade ao ambiente em que o indivíduo se insere (Hondeghem, Horton, \& Scheepers, 2006).

A posição dos gestores, disposta na Figura 5, nos permite identificar que os paradigmas da administração científica e burocrática ainda fazem parte da cultura organizacional do Hospital em estudo. A preocupação com o não prejuízo no posicionamento de E2, a visão não sistêmica dos servidores exposta na fala de E3 sobre a "fragmentação" dos setores, inclusive, as percepções diferenciadas dos gestores sobre os desafios demonstram que o que se vive é aquilo que teoriza o tradicional departamento de pessoal e recursos humanos (Ferreira, 2001).

A análise dos dados obtidos, a partir da percepção dos gestores definidos como sujeitos de pesquisa, permite o entendimento de que no HU/UFSC, mesmo após adesão da EBSERH, não há definição de uma política específica para a gestão de pessoas. Tem-se no momento, a urgência em administrar os recursos humanos, visto que, a preocupação maior está em suprir a lacuna de falta de pessoal ocasionada pela demissão dos profissionais fundacionais.

Nesse entendimento, há a demanda pelo estabelecimento de uma gestão estratégica de pessoas; de diagnóstico de padrões culturais; de gestão de processos de captação, de formação, de movimentação e desenvolvimento de pessoas; de gestão das relações de trabalho e da qualidade de vida no trabalho e gestão de competências (Fleury \& Fischer, 1998). Todavia, é importante relembrar que este estudo está tratando do momento de transição de gestão do HU/UFSC para a EBSERH e que esse foi um processo difícil e conflituoso. Compreende-se que os gestores estão administrando as primeiras consequências da ação e, sendo assim, não está se afirmando que não há preocupação com a gestão de pessoas, inclusive o discurso dos entrevistados traz subjetivamente essa vontade, ademais, sabe-se que esse é um processo que necessita de planejamento, para implementação futura.

\section{Considerações Finais}

A partir da problematização evidenciada por esta pesquisa, ou seja, a de gestão de pessoas em um hospital universitário federal e a implantação de um novo modelo de gestão hospitalar por parte do Governo Federal para administração de tais instituições, com a criação de uma empresa pública para tal finalidade, este estudo teve como conhecer a percepção dos gestores de um Hospital Universitário, em termos de gestão de pessoas, após adesão à EBSERH.

Com o intuito de alcançar o objetivado, buscou-se conhecer, por meio de entrevista, a opinião dos principais gestores do hospital - Direção Geral, os quais, além de estarem à frente da administração, 
estiveram envolvidos diretamente no processo de adesão. Observa-se que os oito gestores responderam aos questionamentos, conforme apresentado na seção 4 deste estudo.

Os dados permitiram verificar a complexidade que permeia a gestão hospitalar, tanto naquilo que se refere à gestão como um todo, quanto na questão de pessoas. Em relação ao processo de adesão, constatou-se a tensão entre a falta de trabalhadores para atender a demanda de serviços e a não possibilidade de permanência dos trabalhadores fundacionais, nem de realização de concursos públicos. O próprio processo de transição de HU/UFSC para EBSERH, diante da forte rejeição da comunidade universitária à adesão, também foi elemento desafiador para os envolvidos no processo.

Todavia, a parir dos dados foi possível identificar que atualmente a administração do hospital em estudo, apenas cumpre aquilo que preconiza a teorização dos recursos humanos tradicional, isto é, os esforços estão direcionados para atender o determinado na regulamentação e, sobretudo, em resolver questões que envolvem a reposição de pessoal - demissões e formas de contratação. Entretanto, é importante considerar o discurso do Entrevistado 5 (2016), quando chama a atenção para a necessidade de capacitação e do Entrevistado 1 (2016), ao comentar as situações de conflitos interpessoais no ambiente de estudo. Ressalta-se que ambos os elementos são estruturantes de estratégias para gerir pessoas nas organizações. Desse modo, considera-se que apesar de a percepção dos sujeitos estar direcionada para o atendimento das legislações e da demanda de pessoal, há uma primeira idealização sobre a necessidade de construção de uma política específica para a gestão de pessoas.

Dentre os limitadores da pesquisa cita-se o próprio momento de transição e tensão vivenciado no ambiente ora explorado, quando na realização da coleta de dados, visto uma realidade configurada por incertezas e forte oposição à adesão. Dessa forma, recomenda-se para estudos futuros, uma análise da conjuntura atual no HU/UFSC, considerado mais de um ano da adesão, sobre a questão de pessoal, com possibilidade de ampliação para outros níveis organizacionais. 


\section{Referências}

Alles, M. A. (2006). Desarrollo del talento humano: basado en competencias. Buenos Aires: Granica.

Bardin, L. (2011). Análise de conteúdo. São Paulo: Edições 70.

Bonacim, C. A. G., \& Araújo A. M. P. (2011). Evaluation of financial performance of health services: reflections of operational policies in the hospital sector. Ciência \& Saúde Coletiva, 16, 1055-1069. Recuperado em 5 janeiro, 2019 de http://www.scielo.br/scielo.php?pid=S141381232011000700038\&script=sci arttext\&tlng=pt

Cahali, Y. S. (2007). Responsabilidade Civil do Estado (3a. ed. rev., atual e ampl.). São Paulo: Ed. Revista dos Tribunais. Creswell, J. W. (2009). Research design: qualitative, quantitative and mixed approaches (3. ed.). London: Sage Publications.

Decreto n. 2.271, de 7 de julho de 1997. (1997). Dispõe sobre a contratação de serviços pela Administração Pública Federal direta, autárquica e fundacional e dá outras providências. Recuperado em 10 janeiro, 2019 de http://www.planalto.gov.br/ccivil_03/decreto/d2271.htm

Decreto n. 7.186, de 27 de maio de 2010. Regulamenta os arts. 298 a 307 da Lei no 11.907, de 2 de fevereiro de 2009, que tratam do Adicional por Plantão Hospitalar - APH. Disponível em: <http://www.planalto.gov.br/ ccivil_03/_ato2007-2010/2010/Decreto/D7186.htm>. Acesso em: 07 janeiro 2019.

Duarte, I. G., \& Botazzo, C. (2014). Gestão de pessoas nas organizações sociais de saúde: algumas observações. RAS, 11 (45), 161-168. Recuperado em 5 janeiro, 2019 de file:///C:/Users/USUARIO/Downloads/161-168gest\%C3\%A3o\%20de\%20pessoas.pdf.

Dutra, J. S. (2002). Gestão de Pessoas: Modelo, Processos, Tendências e Perspectivas. São Paulo: Atlas.

Empresa Brasileira de Serviços Hospitalares [EBSERH]. (2014). Regimento Interno. Recuperado em 10 janeiro, 2019 de http://www.ebserh.gov.br/documents/15796/112576/regimento_interno_segunda_revisao_com_ siglas_09122014.pdf/0ffb9c48-695f-46a3-955d0e9fbded57c0.

Empresa Brasileira de Serviços Hospitalares [EBSERH]. (2016a). Contrato. Recuperado em 10 janeiro, 2019 de http://www.ebserh.gov.br/documents/15796/1059101/contrato+ufsc.pdf/1a977d91-8d86-40f0-abcef2494eb849f4.

Empresa Brasileira de Serviços Hospitalares [EBSERH]. (2016b). Dimensionamento de Serviços Assistenciais. Recuperado em 10 janeiro 2019 de http://www.ebserh.gov.br/documents/15796/1059101/ Dimensionamento+de+Servi\%C3\%A7os+-+HUPEST-UFSC.pdf/3ba538d1-4c0d-4522-b6d4-28f99653be44 Ferreira, V. C. P. (2001). Gestão com pessoas. FGV Editora.

G1 Santa Catarina. (2016). UFSC assina contrato de adesão à Ebserh para reestruturar o HU. Recuperado em 10 janeiro, 2019 de http://g1.globo.com/sc/santa catarina/noticia/2016/03/ufsc-assina-contrato-de-adesaoebserh-para-reestruturar-o-hu.html

Gil, A. C. (2010). Como elaborar projetos de pesquisa. São Paulo: Atlas. 
Hondeghem, A., Horton, S., \& Scheepers, S. (2006). Modelos de gestão por competências na Europa. Revista do Serviço Público. Brasília, 57 (2), 241-258, 2006. Recuperado em 2 janeiro, 2019 de https://revista.enap.gov. br/index.php/RSP/article/view/198

Leal, F. G., \& Dalmau, M. B. L. (2014). Análise das competências secretariais requeridas pela Universidade Federal de Santa Catarina em comparação ao perfil profissiográfico do secretário executivo. Revista de Gestão e Secretariado, 5 (3), 144-174. Recuperado em 2 janeiro, 2019 de https://www.revistagesec.org.br/ secretariado/article/view/289

Lei no 8.958, de 20 de dezembro de 1994. (1994). Dispõe sobre as relações entre as instituições federais de ensino superior e de pesquisa científica e tecnológica e as fundações de apoio e dá outras providências. Recuperado em 10 janeiro, 2019 de http://www.planalto.gov.br/ccivil_03/LEIS/L8958.htm

Lei no 12.550, de 15 de dezembro de 2011. (2011). Autoriza o Poder Executivo a criar a empresa pública denominada Empresa Brasileira de Serviços Hospitalares EBSERH. Recuperado em 10 janeiro, 2019 de http://www. planalto.gov.br/ccivil 03/ Ato2011-2014/2011/Lei/L12550.htm

Martins, S. P. (2007). Direito do trabalho. 23 ed. São Paulo: Atlas.

Meirelles, H. L. (1997). Direito municipal brasileiro. 9. Ed. São Paulo: Malheiros.

Morais, P. (2016). Impacto do Marketing Digital nas organizações. Recuperado em 10 janeiro, 2019 de https://www. marketingportugal.pt/artigos/marketing-digital/marketingdigital-nas-organizacoes

Moreira, K. D. (2012). A mediação como método de resolução de conflitos interpessoais na Universidade Federal de Santa Catarina. Dissertação de Mestrado, Florianópolis, Santa Catarina, Brasil.

Paula, R. B. (2016). Desafios da gestão do HU/UFSC, após a criação da EBSERH pelo governo federal. Dissertação de Mestrado, Florianópolis, Santa Catarina, Brasil.

Ribeiro, D. B., Bolzan, D., Littike, D., \& Sodré, F. (2010). Reflexões sobre demandas atendidas pelo serviço social no Núcleo de Atenção à Saúde do Trabalhador. Anais do Encontro Nacional de Política Social. Vitória, Espírito Santo, Brasil.

Robbins, S. P. (2001). Administração: mudanças e perspectivas. São Paulo: Saraiva.

Tribunal de Contas da União [TCU]. (2011). Acórdão 2681/2011: Substituição de terceirizados irregulares por servidores efetivos no âmbito de órgãos e entidades da administração pública federal direta, autárquica e fundacional. Prorrogação de prazo para a finalização do processo de substituição. Alerta aos órgãos e entidades sobre a possibilidade de responsabilização por atos omissivos ou comissivos dos gestores. Recuperado em 10 janeiro, 2019 de http://audin.ufsc.br/acordaos-tcu-contratacaoirregular-de-funcionariosterceirizados/

Tribunal de Contas da União [TCU]. (2015). Acórdão 2983-46/2015. Auditoria Operacional realizada na Empresa Brasileira de Serviços Hospitalares com o objetivo de avaliar as ações voltadas para melhoria da gestão e da infraestrutura dos Hospitais Universitários Federais, bem como avaliar a substituição dos terceirizados que 
atuam com vínculo precário nas unidades hospitalares. Recuperado em 10 janeiro, 2019 de https://contas. tcu.gov.br/juris/SvlHighLight

Universidade Federal de Santa Catarina [UFSC]. (2014). ADRH: Sistema para gerenciar os procedimentos administrativos relacionados aos recursos humanos da UFSC. Recuperado em 10 janeiro, 2019 de https:// contas.tcu.gov.br/juris/SvlHighLight

Universidade Federal de Santa Catarina [UFSC]. (2013). Hospital Universitário Professor Polydoro Ernani de São Thiago. Boletim Estatístico do Movimento Hospitalar do Exercício 2012 - Seção de Arquivo e EstatísticaFlorianópolis: HU/UFSC.

Vergara, S. C. (2007). Projetos e relatórios de pesquisa em administração. São Paulo: Atlas S.A. 